\title{
MAPPING THE EXTENT AND MAGNITUDE OF SEVER FLOODING INDUCED BY HURRICANE IRMA WITH MULTI-TEMPORAL SENTINEL-1 SAR AND INSAR OBSERVATIONS
}

\author{
B. Zhang ${ }^{1 *}$, S. Wdowinski ${ }^{1}$, T. Oliver-Cabrera ${ }^{2}$, R. Koirala ${ }^{1}$, M. J. Jo ${ }^{3}$, B. Osmanoglu ${ }^{4}$ \\ ${ }^{1}$ Florida International University, Miami, FL, 33199 USA - (bzhan018, swdowins, rkoir001)@ fiu.edu \\ 2 Rosentiel School of Marine \& Atmosphere Science, University of Miami - toliver@ rsmas.miami.edu \\ ${ }^{3}$ USRA, NASA-GSFC, Greenbelt, MD, 20771 USA - minjeong.jo@ nasa.gov \\ ${ }^{4}$ NASA-GSFC, Greenbelt, MD, 20771 USA - batuhan.osmanoglu@nasa.gov
}

Commission III, WG III/2

KEY WORDS: Flood, SAR, InSAR, Multi-temporal, Hurricane, Florida

\begin{abstract}
:
During Hurricane Irma's passage over Florida in September 2017, many sections of the state experienced heavy rain and sequent flooding. In order to drain water out of potential flooding zones and assess property damage, it is important to map the extent and magnitude of the flooded areas at various stages of the storm. We use Synthetic Aperture Radar (SAR) and Interferometric SAR (InSAR) observations, acquired by Sentinel-1 before, during and after the hurricane passage, which enable us to evaluate surface condition during different stages of the hurricane. This study uses multi-temporal images acquired under dry condition before the hurricane to constrain the background backscattering signature. Flooded areas are detected when the backscattering during the hurricane is statistically significantly different from the average dry conditions. The detected changes can be either an increase or decrease of the backscattering, which depends on the scattering characteristics of the surface. In addition, water level change information in Palmdale, South Florida is extracted from an interferogram with the aid of a local water gauge as the reference. The results of our flooding analysis revealed that the majority of the study area in South Florida was flooded during Hurricane Irma.
\end{abstract}

\section{INTRODUCTION}

During Sep $10^{\text {th }}$ to Sep $13^{\text {th }} 2017$, Hurricane Irma, a catastrophic Category 5 hurricane, made landfall over Florida, causing severe flooding, which led to damage to properties and many death tolls in Florida. A major part of economic loss by the hurricane was attributed to flooding, which is induced by both heavy rainfall and storm surge. Since flooding can cause severe damage, flood monitoring and mapping is vital for authorities and decision-makers for water management and estimation of risks and economic loss. In addition, mapping flood extent and magnitude can provide valuable distributed calibration and validation information for hydraulic models of river flow processes (Mason et al. 2015).

While mapping the extent and magnitude of flooding is important, it remains a challanging task. Currently, authorities rely heavily on the water gauges, which provide high temporal measurements of water levels. However, gauges are normally distributed sparsely, expensive to operate, and vulnerable to vandalism and hurricane strength winds. Optical remote sensing observations have been widely used to map flooding (e.g., Townsend and Walsh, 1998; Celik, 2010). However, they are inefficient during hurricane passages due to the hurricane's thick cloud coverage. Radar remote sensing, as Synthetic Aperture Radar, which operates at all weather conditions, provide useful observations for flood mapping under cloud cover conditions. SAR-based detection also been widely used for detecting flood extent (e.g., Matgen et al. 2010; Horritt et al. 2001; Pulvirenti et al. 2011). These methods use the amplitude observations, which can detect lateral changes in scattering environment due to inundation. The detection of flooding extent relies on several mapping algorithms (Matgen et al. 2011), including visual interpretation (Oberstadler et al. 1997), image texture algorithms (Schumann et al. 2005), image segmentation (Pulvirenti et al. 2011), histogram thresholding (Martinis et al. 2009), statistical active contour modeling (Horritt et al. 2001) and multi-temporal change detection method (Townsend, 2001).

In order to detect the flooding magnitude, SAR phase information becomes useful, as it can detect water level changes over wetlands with emergent vegetation (e.g., Wdowinski et al. 2004; 2008; Kim et al. 2005; Gondwe et al. 2010; OliverCabrera and Wdowinski, 2016). The detection of water level changes requires interferometric SAR (InSAR) data processing. Oliver-Cabrera and Wdowinski (2016) have used ALOS and Radarsat-1 data to generate detailed maps of water level changes in the tidal zone in Louisiana Coastal Wetlands. In addition, Lu and Kwoun (2008) have conducted European Remote Sensing 1 and 2 (ERS-1/ERS-2) and Radarsat-1 InSAR to study water level changes beneath swamp forests of coastal wetlands of southeastern Louisiana.

Previous SAR-based flooding detection studies used various satellites, including the ERS-1/ERS-2, ENVISAT, Radarsat-1, TerraSAR-X, COSMO-SkyMed (Townsend, 2001; Bazi et al. 2005; Mason et al. 2010; Oberstadler et al. 1997; Pulvirenti et al. 2011). In the past three years, more and more attention has been drawn by Sentinel-1 A and B satellites, which were launched in April 2014 and April 2016 respectively by European Space Agency (ESA) in the frame of the European Union's Copernicus Program (Twele et al. 2016). Both of the satellites are equipped with C-band SAR, and the interferometric wide swath (IW) is the by default mode, which acquires the image in a dual-polarized manner with $\mathrm{VV} / \mathrm{VH}$ polarization. 
In this study, for the flood extent mapping, we take advantage of Sentinel datasets and use a quantitative statistical method based on multi-temporal datasets. The method can not only distinguish the flooded and nonflooded areas, but also provide the confidence of flooding detection for every single pixel. Next, we use one image acquired during the Hurricane Irma and another one after to form an interferogram, and extract the water level change information of a region named Palmdale in South Florida. In the end, we use Everglades Depth Estimation Network (EDEN) data to verify our results of flooding extent mapping.

\section{STUDY AREA}

The study area is part of the southernmost Florida, which features subtropical climate. Everglades national park locates in this region, and it includes pine rocklands, wetland, large areas of marshes, prairies and linear shaped sloughs. Marshes take a remarkable proportion, and they are periodically or continually inundated, depending on hydroperiod. In addition, Big Cypress National Preserve locates in the northwest to Everglades national park, and it features hammocks, cypress swamps, mangroves and marshes. Moreover, Florida mangroves ecosystem locates along the coasts of the Florida Peninsula and also Florida keys. The urban locates along both the east and west coasts, and it has a relatively smaller proportion of area than the countryside. The coverage of two study areas are shown in Figure 1 as below.
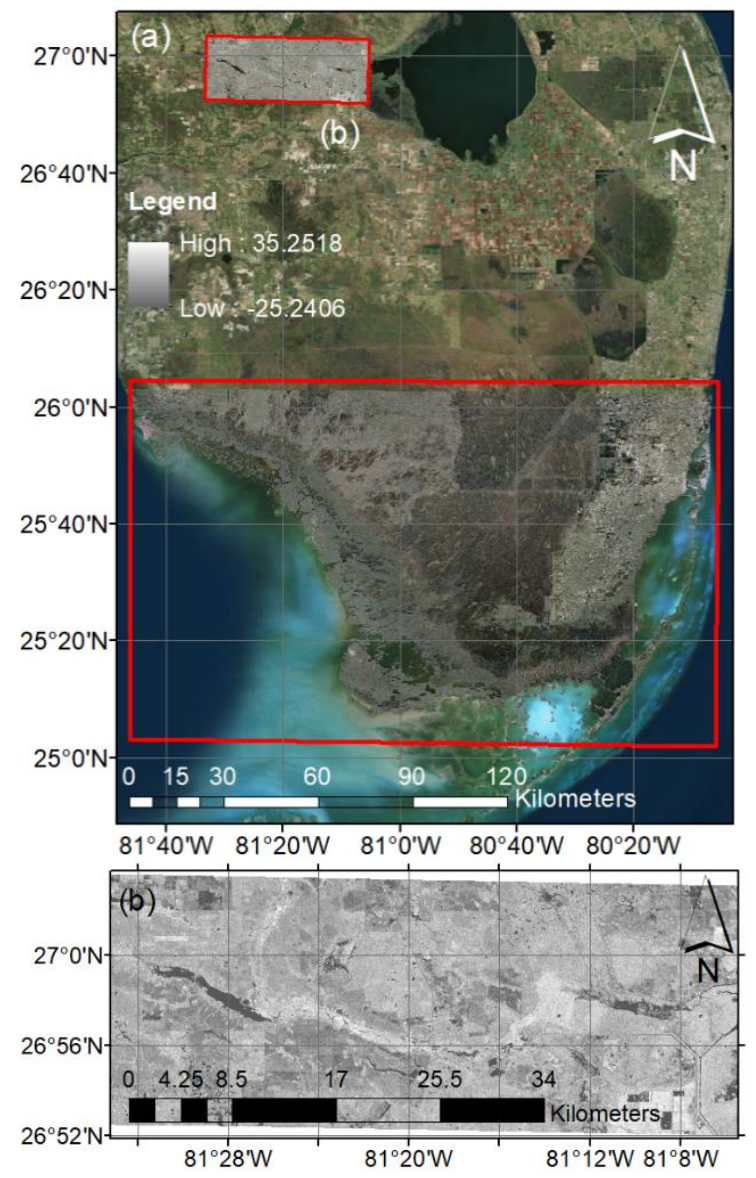

Figure 1. (a) Location map of our two study areas within two red frames in south Florida. Both areas are shown as SAR amplitude images that overlay a Google Earth satelite image as background. The southern study area consists of the Everglades
National Park and surounding areas and the northern study area consists of Palmdale wetlands. (b) A close up image of the northern study area.

\section{METHODOLOGY}

We map both the extent and magnitude of the flooding conditions induced by Hurricane Irma, during its passage over Florida in September 2017. Our research is based on Sentinel$1 \mathrm{~A}$ and Sentinel-1B datasets. We assume two scenarios of backscattering on the surface during the flooding event, and it is shown in Figure 2 as below:
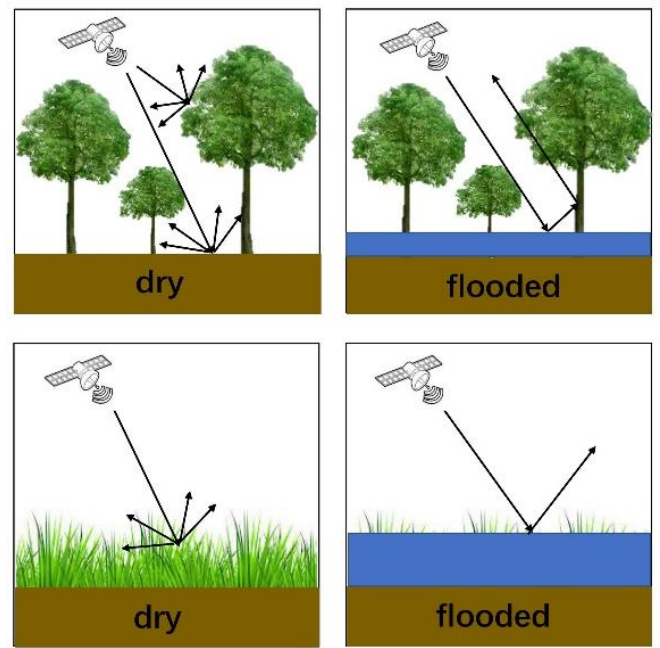

Figure 2. Backscattering characteristics of tall and short vegetation land covers under dry and flooded conditions. Notice that flooded conditions increase backscattering in tall vegetation due to double bounce scattering, but reduces the scattering in short vegetation areas (after Bourgeau-Chavez et al. 2005).

The first row shows the scenarios in tall plants like forests, and the second row scenarios in short plants. For the first row, when dry, there is only backscatter from the soil or tree. However, when flooded, SAR will receive double bounce signal. If the forest is very dense, then there will no difference between the dry and wet conditions, since C-band is not able to penetrate the forest canopy. For the second row, when the short plants vegetation like marshes are flooded, the signal will reflect away from SAR, and the received signal could be very weak.

\subsection{Mapping Flooding Extent}

We developed a statistical method to detect the extent of flooding independent of surface scattering conditions, using a pixel to pixel approach. A test quantity $t$ is formed as below:

$$
t=(W-[D]) / \sigma
$$

where $\quad t$ is the normalized scattering change value

$W$ is pixel value in the wet image

[] is the average operator

$[D]$ is average value of each pixel from all the three dry images

$\sigma$ is standard deviation of each pixel representing the deviation among the dry images

We calculate $\sigma$ of each pixel from all the dry images. The test quantity $t$ indicates the separability of pixel value between the wet and dry conditions. $t$ represents the signal-to-noise ratio 
(SNR) of each pixel. When the difference between wet and average dry image is larger than $1 \sigma$, then flooding is detectable, because the difference is significantly larger than the background noise. Otherwise, it is non-flooded or undetectable, due to the relatively large noise.

By thresholding on test quantity $t$, we set three classes. First, when $t>1$, which means $W-[D]$ is larger than $1 \sigma$, there is significant increase of backscattering, and flooding is detected due to double bouncing. Second, when $t$ is between -1 and 1 , i.e., absolute value of $W-[D]$ is smaller than $1 \sigma, W-[D]$ cannot be distinguished from the background noise. Thus, it is classified as 'Non-flooded or Undetectable'. At last, when $t<-1$, absolute value of $W-[D]$ is significantly larger than $1 \sigma$ as well, and flooding is detected due to signal reflecting away from water surface.

\subsection{Estimating Flooding Magnitude}

Two SLC datasets are used to form a interferogram. First, they are coregistered with subpixel level, and the interferogram is formed. Next, we deburst the image and merge the subswath. Though Florida is generally flat, we still remove the topographic phase in order to be more precise. Unwrapping result from Statistical-Cost, Network-Flow Algorithm for Phase Unwrapping (SNAPHU) was wrong because of the low SNR in the surrounding area. Consequently, we manually unwrapped the interferogram by counting the number of fringes.

The unwrapped interferogram is converted to vertical water level change by Eq. (2).

$$
L=\frac{\varphi_{u n w} \lambda}{-4 \pi \cos \theta}
$$

where $\quad L$ is the water level change in meter unit $\varphi_{\text {unw }}$ is unwrapped phase in radian unit $\lambda$ is wavelength, i.e., $5.6 \mathrm{~cm}$ $\theta$ is the incidence angle

This method results in a temporally and spatially relative water level change image. In the end, we use a water gauge locating in the study area to calibrate all the relative measurements to absolute measurements.

\section{DATA AND DATA PROCESSING}

This study uses Sentinel-1 SAR data acquired in C-band. This constellation consists of two satellites, Sentinel-1A and Sentinel-1B in the same orbit plane (after ESA Sentinel Online, https://Sentinel.esa.int/web/Sentinel /missions/Sentinel1/overview). Comparing with the constellations mentioned above, Sentinel-1 products are more applicable to flooding mapping in terms of the high revisit frequency. The revisit period is only 12 days for each satellite, 6 days for the combined constellation, and product delivery is rapid, which makes it a good resource for flood monitoring. The C-band microwave is able to penetrate clouds and work regardless of weather conditions during day and night. In order to study the backscatter signature of land surface on both wet and dry conditions, we use 4 Sentinel-1A acquisitions for flooding extent mapping, all of which were acquired on ascending pass direction. The data is in GRD format, and the spatial resolution is $20 * 22 \mathrm{~m}$ for range and azimuth. Multi-temporal datasets are used since we want to constrain the backscattering signature on the dry condition, and it provides a reference to further detect the flooded areas. Moreover, one Sentinel-1A and one Sentinel1B Single Look Complex (SLC) acquisitions are used for magnitude mapping, and both of them were acquired on descending pass direction. The spatial resolution is 2.7-3.5* $22 \mathrm{~m}$ (depending on incidence angle) for range and azimuth. All the images were acquired in 2017 during the summer season. In addition, we use only the VV polarization. The accuracy of VV polarization of Sentinel data is slightly higher than that of $\mathrm{VH}$ polarization, since $\mathrm{VH}$ polarization has higher backscatter variability of scatters on land and low level of backscatter of vegetated area, which could be interpreted as water body (Twele et al. 2016). The basic information of all acquisitions are summarized in Table 1.

\begin{tabular}{|l|l|l|l|l|}
\hline ID & Date & Weather & $\begin{array}{c}\text { Use of } \\
\text { Mapping }\end{array}$ & $\begin{array}{l}\text { Data } \\
\text { Format }\end{array}$ \\
\hline 1 & Jul $24^{\text {th }}$ & Dry & Extent & GRD \\
\hline 2 & Aug $17^{\text {th }}$ & Dry & Extent & GRD \\
\hline 3 & Aug $29^{\text {th }}$ & Dry & Extent & GRD \\
\hline 4 & Sep $10^{\text {th }}$ & Wet & Extent & GRD \\
\hline 5 & Sep $12^{\text {nd }}$ & Wet & Magnitude & SLC \\
\hline 6 & Sep $18^{\text {th }}$ & Dry & Magnitude & SLC \\
\hline
\end{tabular}

Table 1. Basic information of all SAR and InSAR acquisitions

In addition, we also used land cover data for analysis. The land cover classification shapefile data is extracted from Florida Fish and Wildlife Conservation Commission. Land covers are dissolved into short plants, tall plants, urban, mangrove and water body. The classification is based on the assumption shown in Figure 2: when flooded, short plants show less normalized radar cross section, or sigma nought, due to reflection, while the rest of land cover classes is expected to have sigma nought increase due to double bouncing. Water class is considered as permanent water body, which is excluded from this study. Figure 3 shows the distribution of four land covers.

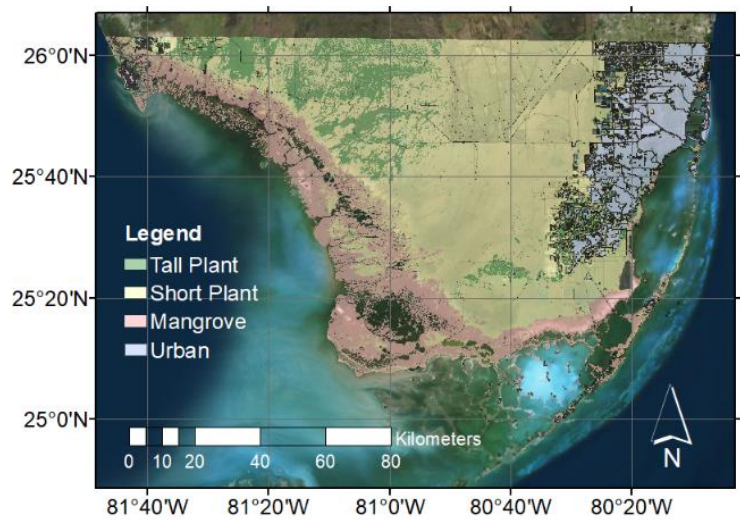

Figure 3. Land covers map of the southern part of the study area, based on four main classes. All the land cover classes are displayed with $40 \%$ transparancy.

At last, for the purpose of validation, we extract water depth data from Everglades Depth Estimation Network (EDEN). We compared water depth distribution map from Cape Sable Seaside Sparrow (CSSS) Viewer, USGS and EDEN water gauges data with our map of flooding extent. We verify our results by calculating the accuracy of flooding detection.

Sentinel Application Platform (SNAP) is used for preprocessing all the SAR images. We follow standardized procedure to process GRD and SLC datasets in order to get sigma nought 
images and interferograms. The diagrams for GRD and SLC preprocessing procedure are shown as below in Figure 4.
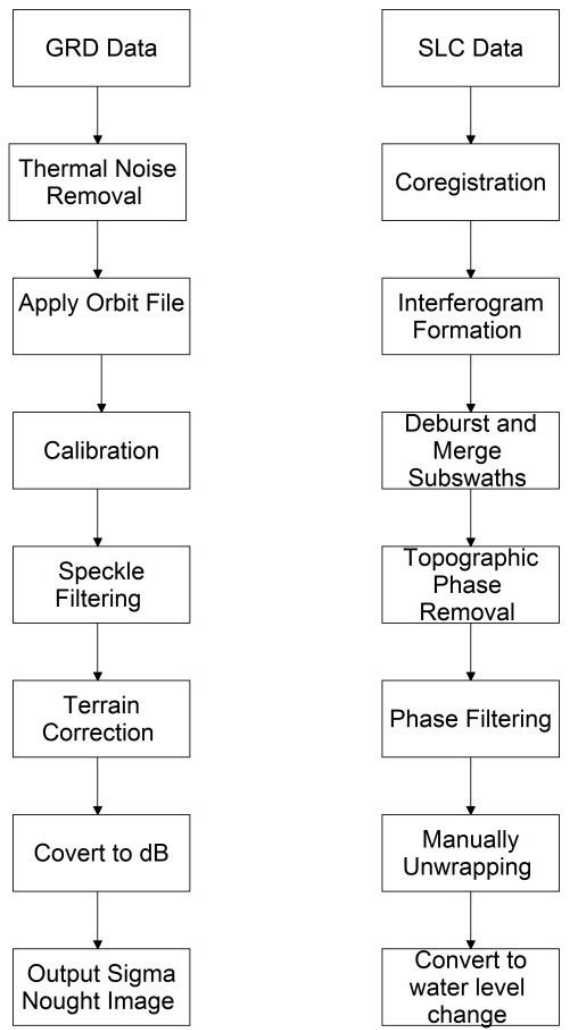

Figure 4. Diagrams of both GRD and SLC data preprocessing steps. The left column is for GRD and the right one is for SLC data resepectively.

For flooding extent mapping, we apply the methodology in Session 3.1 on the output sigma nought image, as shown in Figure 4. The results for both extent and magnitude mapping are shown in Session 5.

\section{RESULTS}

\subsection{Flooding Extent Mapping}

This session demonstrates result of delineating flooding extent. Based on the multi-temporal data, we develop a quantitative way to detect the flooded area by thresholding on pixel value, i.e. sigma nought. This method takes into account contributions from various scattering environments. The whole process is implemented in ArcGIS 10.4 software. We use the three prehurricane images to calculate the background scattering characteristics in "dry" conditions. The background scattering level varies in the range of $-20 \mathrm{~dB}$ to $30 \mathrm{~dB}$, depending on the scattering environments. The average image of the three dry images is first calculated by land cover. Next, based on the result, we averages all the pixels within one land cover. Consequently, we gain a temporal spatial average for each land cover. In addition, the spatial average of the four land covers in the wet image (acquired during Hurricane Irma) is calculated as well. Table 2 below shows the comparison between the two averages by land cover:

\begin{tabular}{|l|l|l|l|}
\hline & Dry & Wet & Wet - Dry \\
\hline Short Plant & -8.43 & -10.22 & -1.79 \\
\hline Tall Plant & -7.76 & -7.14 & 0.62 \\
\hline Mangrove & -8.64 & -7.85 & 0.79 \\
\hline Urban & -8.47 & -7.54 & 0.93 \\
\hline
\end{tabular}

Table 2. Average dry and wet scattering values according to the four land cover classes (unit: $\mathrm{dB}$ )

Table 2 shows sigma nought decreases in the short plants and increases in the other three land covers by comparing the wet image with the average of dry images. For all land covers, the difference is around -2 to $1 \mathrm{~dB}$. It is consistent with the assumption that short plant was submerged by the flooding, which causes reflection of the radar signal, while double bouncing occurred on tall plants, urban and mangroves, resulting in increase of backscattering.

Next, after applying the methodology in 3.1 , we are able to get the distribution of flooding extent with confidence of detection. Figure 5 below shows the distribution of different classes of the normalized scattering change value $t$.

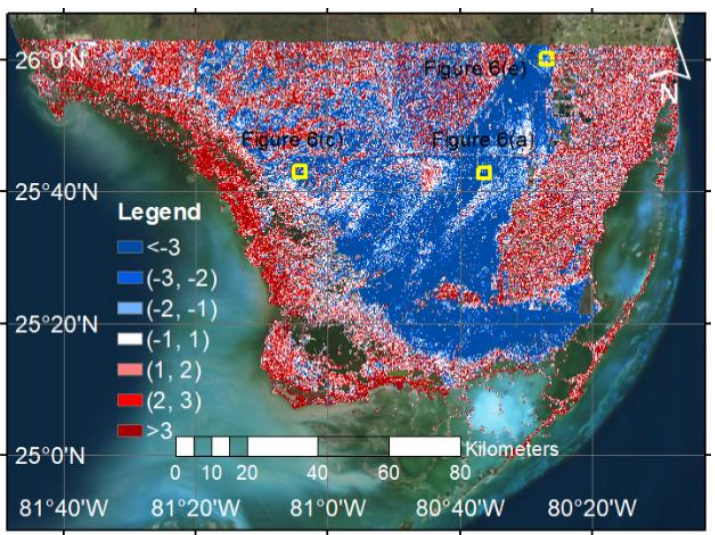

Figure 5. Normalized scattering change values mapped according to the detection confidence. Blue pixels show detected scattering decrease, red pixel show detected increase, and white pixel indicates the change is not significant, i.e. nonflooded or undetectable. The shades of blue and red mark the detection confidence, as presented in Table 3. Yellow frames mark the zoomed-in areas presented in Figure 6.

\begin{tabular}{|l|l|l|}
\hline Range of $t$ value & Color & Meaning \\
\hline$t<-3$ & Deep Blue & $\begin{array}{l}\text { Flooding ( >99.7\% } \\
\text { confidence) }\end{array}$ \\
\hline$-3<t<=-2$ & Middle Blue & $\begin{array}{l}\text { Flooding (95- } \\
99.7 \% \text { confidence) }\end{array}$ \\
\hline$-2<t<=-1$ & Light Blue & $\begin{array}{l}\text { Flooding (68-95\% } \\
\text { confidence) }\end{array}$ \\
\hline$-1<t<=1$ & White & $\begin{array}{l}\text { Non-flooded or } \\
\text { Undetectable }\end{array}$ \\
\hline $1<t<=2$ & Light Red & $\begin{array}{l}\text { Flooding (68-95\% } \\
\text { confidence) }\end{array}$ \\
\hline $2<t<=3$ & Middle Red & $\begin{array}{l}\text { Flooding } \\
99.7 \% \text { confidence) }\end{array}$ \\
\hline$t>3$ & Deep Red & $\begin{array}{l}\text { Flooding ( >99.7\% } \\
\text { confidence) }\end{array}$ \\
\hline
\end{tabular}

Table 3. Classes of normalized scattering changes according to the color ramp in Figure 5

Table 3 shows that for both detected increase and decrease $t$, we divided into 3 subclasses according to the absolute value of $t$, which matches with the graded shades of red and blue colors. 


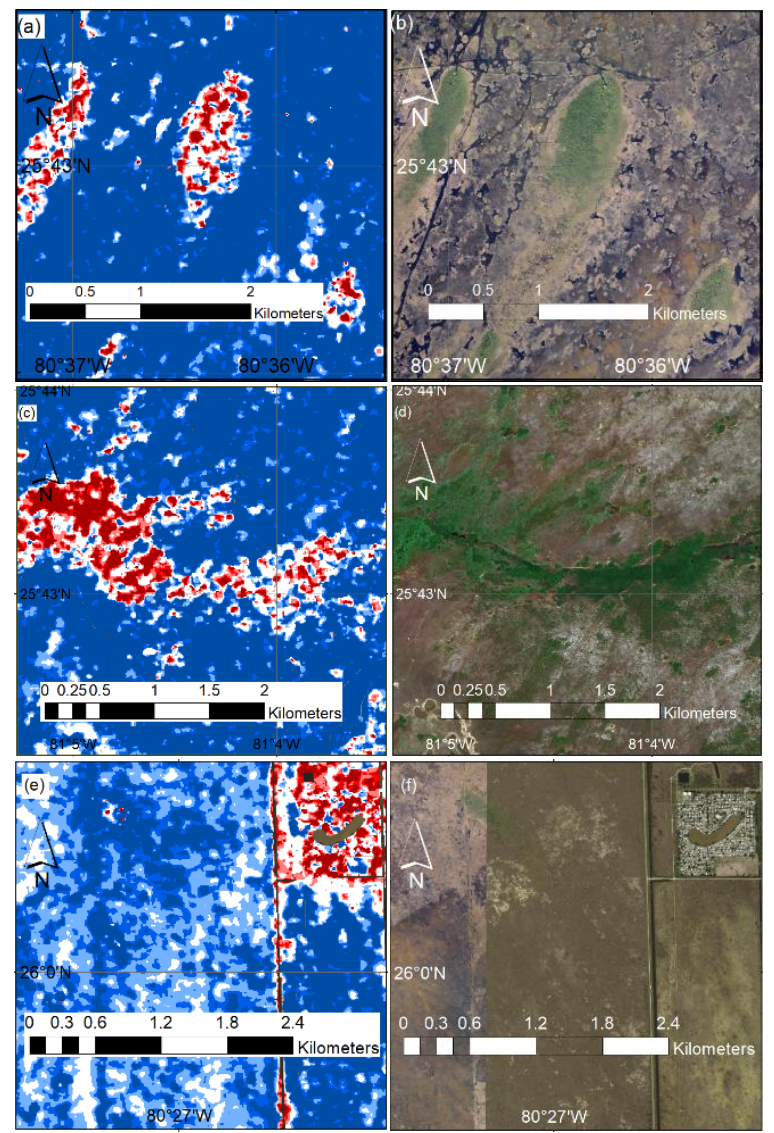

Figure 6. Normalized scattering change values $(t)$ and their land cover characteristic obtained from satellite images in three selected locations. (a), (c) and (e) are zoom-in view of three yellow frames in Figure 5. (b), (d), (f) are the corresponding optical remote sensing images. The color ramp of the normalized changes is the same with Figure 5. (a) and (b) Changes in the northern Shark Valley Slough showing scattering decrease over short vegetation, scattering increase over tree islands with tall vegetation (c) and (d) Changes in the western Everglades showing mostly scattering increase over forests and scattering decrease over areas with short vegetation. (e) and (f) Changes in eastern Everglades along the boundary with urban area, demonstrating scattering increase in the up right corner urban area and scattering decrease for the rest of the image. The elevated linear shape structure also shows increased backscattering.

Figure 6 shows three types of environment. What is common among the three is the varying land covers mixing together. Figure 6 well indicates the effectiveness of the proposed mapping method. For example, subplot (a), (c) and (e) clearly show colors in contrast between the short plant (marsh) and tree islands, forest and urban area. Subplots (b), (d) and (f) provide the evidence of the distribution of different land covers. Obviously, majority of the features in (a), (c), (e) match well with features in (b), (d), (f). The backscattering behavior is consistent with the assumption shown in Figure 2. Next, Figure 7 shows the binary mapping of flooding extent.

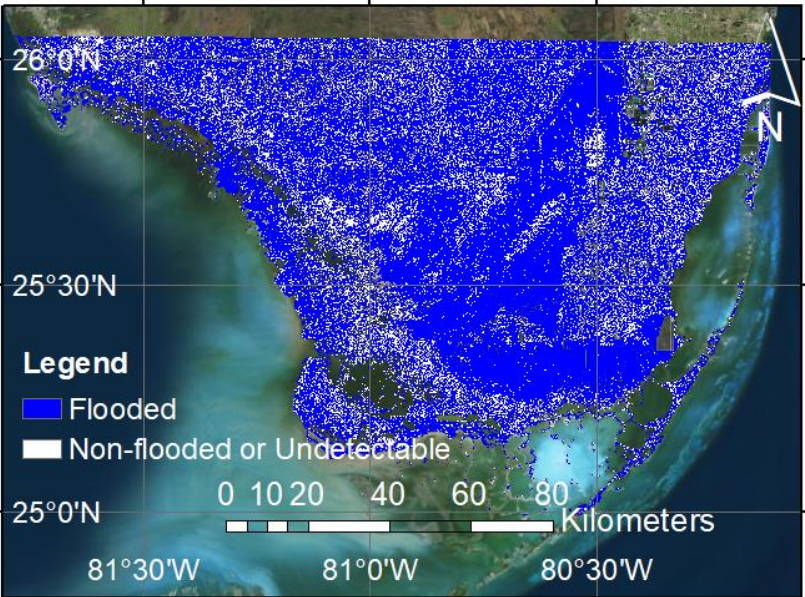

Figure 7. Binary map showing the extent of flooding induced by hurricane Irma. Blue indicates all the flooded areas, which is the sum of flooding area in Figure 5. White color indicates nonflooded or undetectable areas.

From Figure 5 and 7, it is clear that the lower middle short plant land cover is submerged (sigma nought decrease), and the other land covers show dominantly double bouncing (sigma nought increase). Thus, it is consistent with assumption and the statistical analysis in the previous parts. In addition, majority of areas of short plants were detected as flooding with higher confidence, while a small portion of areas in the other three land covers are classified as non-flooded or undetectable. This is because for the mangrove and other tall plants, even though double bouncing is the dominant mechanism controlling the backscattering, there are other factors, such as wind effects, defoliation and trees falling down during Hurricane Irma. In addition, strong precipitation induces signatures in SAR images as well (Danklmayer and Chandra, 2009). However, in this case study, these effects are not strong and remarkable.

It is worth noticing that all the datasets used in this study are acquired during summer season in order to minimize the standard deviation, i.e. the spread of backscattering. In the beginning we included another three SAR image acquired during spring 2017 in the multi-temporal datasets, but the standard deviation is increased due to signal of seasonality, and hence absolute value of $t$ decrease, resulting in significantly more areas fall into non-flooded or undetectable class. Thus, adding more images acquired from other seasons does not help constrain the backscattering signature, and makes the detectability much less.

\subsection{Flooding Magnitude Mapping}

We use two SLC images, acquired in Sep $12^{\text {nd }}$ and $18^{\text {th }}$ respectively as shown in Figure 1b, to form an interferogram in a region called Palmdale in South Florida. We choose this place because of sparse density of forest which makes possible signal double bouncing during the hurricane. Double bouncing results in good coherence betwen these two acquisitions. The interferogram is shown as below in Figure 8. 

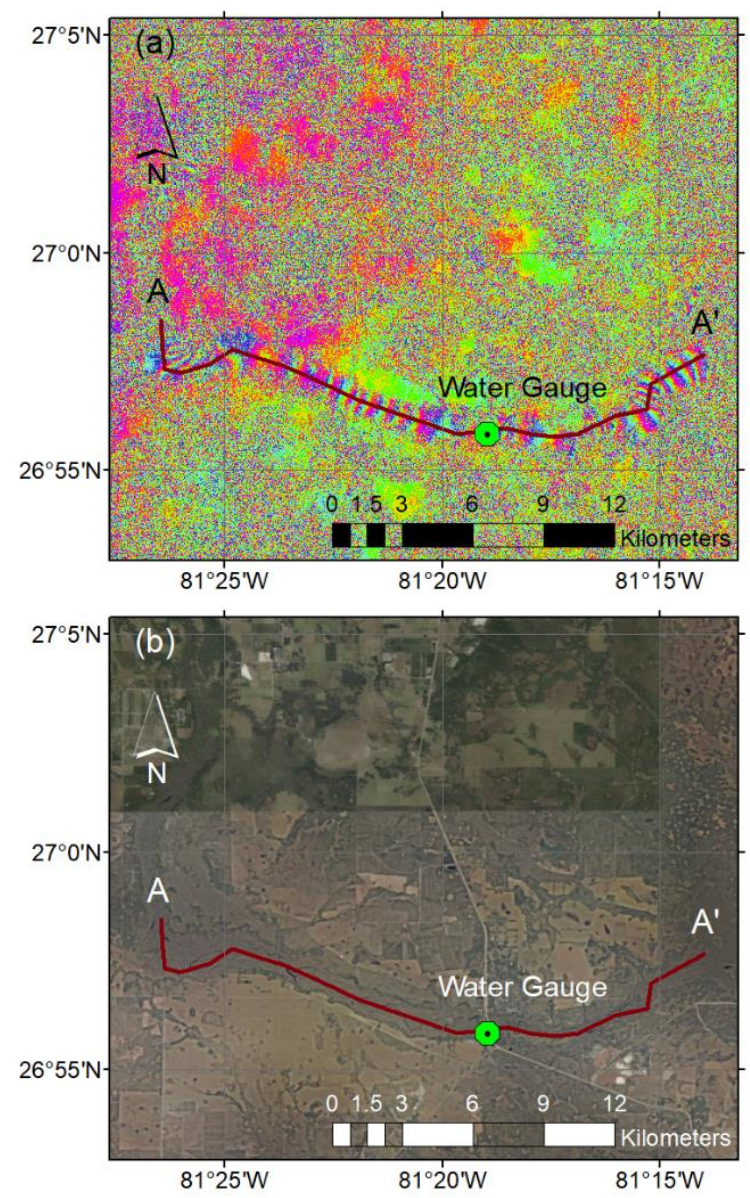

Figure 8. (a) Interferogram in Palmdale. A-A' is the transect for the forested area. (b) The optical satellite image of the same area. The forested wetland is visible from the image.

Since the unwrapped phase and water level changes are temporally and spatially relative measurements, we need an water gauge with absolute measurements to calibrate the whole area. A United States Geological Survey (USGS) water gauge was found and the location is marked in Figure 8. The site number is 02256500 , and the site name is 'FISHEATING CREEK AT PALMDALE, FL'. The unwrapped phase with water level changes and water gauge time series are plotted in Figure 9(a) and 9(b) respectively.

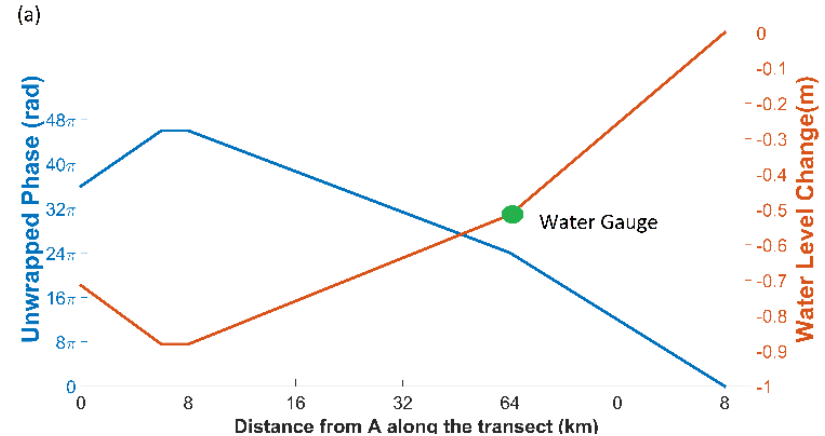

(b)

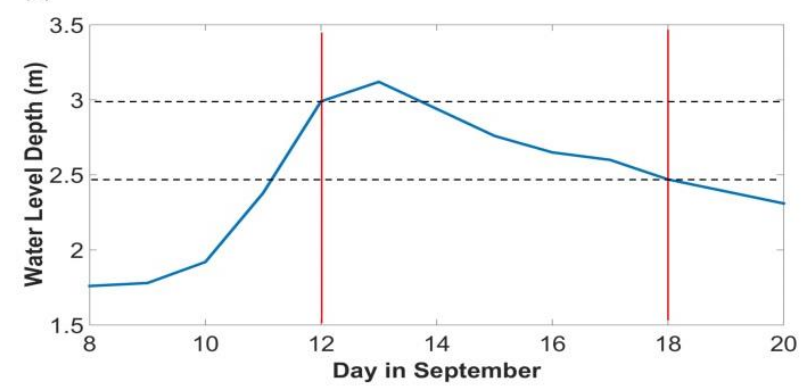

Figure 9. (a) Unwrapped phase and calibrated water level along the Plamdale forested wetland transect (red transect in Figure 8). The green circle marks the position of the water gauge on the transect. (b) Water level time series of the gauge between Sep $8^{\text {th }}$ and $20^{\text {th }}$ (after USGS National Water Information System). Two red vertical lines mark the acquisition times of two SAR SLC images (Sep $12^{\text {nd }}$ and $18^{\text {th }}$ ) used to form the interferogram shown in Figure 8.

As shown in Figure 9(b), this gauge is able to provide precise water level change between two acquisition time points, which is $0.515 \mathrm{~m}$. Consequently, the water level change of the whole forested wetland area between these two acquision times is solved by calibration with the water gauge measurement, as illustrated in Figure 9(a). This method expands the precise measurement of one single water gauge to an area as large as 29 square kilometers meander area.

From Figure 9(a), the western side of transect has more water level change than the eastern side. We can conclude that from Sep $8^{\text {th }}$ to $13^{\text {rd }}$, the water level has been accumulating, as shown in Figure 9(b). The western side of the transect could have a higher water level than the eastern side in Sep $12^{\text {nd }}$ when the first image is acquired. After 6 days, the water flew out and became flat surface, and resulted in more water level change in the western side of transect than the eastern side. The water flow during this period of time was eastward, all the way down to Lake Okeechobee.

\section{FLOODING EXTENT VALIDATION}

We use data from EDEN as a reference to verify our own extent of flood. Figure 10 shows the validation zone, where EDEN indicates the whole zone has a higher water depth within the rectangle shaped zone. 


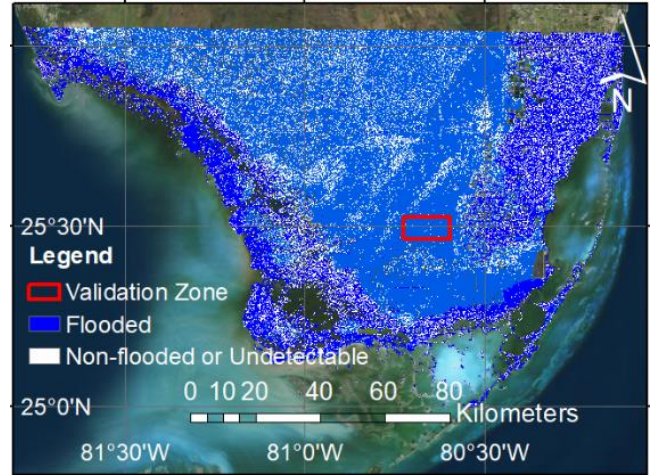

Figure 10. The validation zone within the red rectangle frame overlaying with extent of flooding map.

The validation zone consists of two land covers- both short plants and tall plants. There is $98.7 \%$ area of short plants is correctly classified as flooded, while $87.7 \%$ area of tall plants is detected as flooded. The statistics of validation is summarized as below in Table 4 .

\begin{tabular}{|l|l|l|}
\hline & $\begin{array}{c}\text { Success rate of } \\
\text { detection }(\%)\end{array}$ & $\begin{array}{c}\text { Rate of } \\
\text { misdectection }(\%)\end{array}$ \\
\hline Short Plants & 98.7 & 1.3 \\
\hline Tall Plants & 87.7 & 12.3 \\
\hline Total & 98.3 & 1.7 \\
\hline
\end{tabular}

Table 4. Results of flooding extent mapping validation

In addition, we compared 20 EDEN water gauges and 10 USGS water gauges with our flooding extent mapping. All of the gauges show the water level was high in Sep $10^{\text {th }} 2017$, which indicates that the surronding area was probably flooded. Our flooding extent mapping has $100 \%$ accuracy comparing with these water gauges.

\section{CONCLUSION}

We use multi-temporal Sentinel-1A and Sentinel-1B datasets to map both extent and magnitude of flooding induced by Hurricane Irma which made landfall in Florida on Sep 10 2017. Four Sentinel-1A datasets are used to delineate the extent of flood. In addition, one Sentinel-1A image and one Sentinel-1B image are used to form an interferogram, the derivative of which is water level change.

The study area is classfied into 4 land covers, which are short plant, tall plant, urban and mangrove. It is assumed that these land covers feature different characteristics of signal responses while flooded. When short plant vegetation is flooded and submerged, it would lead to decrease of backscattering, while double bouncing occurs on the other three land covers, and thus increase of backscattering.

First, we take a quantitative approach to delineate the extent of flooding. The average of all three dry images is calculated by land cover. By comparing with the wet image, it is found that the sigma nought change is consistent with the assumption. Next, we use $t=(W-[D]) / \sigma$ to statistically detect the separability between wet and average dry images in a pixel-bypixel manner, generating map of flooding extent with the confidence of detection. We found that majority of the study area is flooded, especially for short vegetation in the middle of the study area. In addition, conspicuous contrast between short plant vegetation like marshes and tall plants vegetation like forest, tree islands and urban area was discovered. It shows the good effectiveness of the flooding detection approach, since different land covers are well distinguished.

At last, SLC data are used for magnitude mapping. In this case, interferograms formed by two SLC images is manually unwrapped. The unwrapped phase infomation is converted to water level change between two acquisitions. A water gauge locating within the study area is used as reference to calibrate the whole study area. The result shows more water level change in the western side of transect than the eastern, which indicates higher water level in the western side in Sep 12 ${ }^{\text {nd }}$. After Sep $13^{\text {rd }}$ when Hurrican Irma faded away, the water level dropped and the accumulated water flew out into Lake Okeechobee.

\section{ACKNOWLEDGEMENT}

The research was supported by the National Science Foundation (NSF) through Research program under Grant No. EAR1713420 and National Aeronautics and Space Administration (NASA) grant 80NSSC17K0098. Sentinel data were provided by European Space Agency (ESA) and Water gauge data were provided by United States Geological Survey (USGS).

\section{REFERENCE}

Bazi, Y., Bruzzone, L. and Melgani, F., 2005. An unsupervised approach based on the generalized Gaussian model to automatic change detection in multitemporal SAR images. IEEE Transactions on Geoscience and Remote Sensing, 43(4), pp.874-887.

Bourgeau-Chavez, L.L., Smith, K.B., Brunzell, S.M., Kasischke, E.S., Romanowicz, E.A. and Richardson, C.J., 2005. Remote monitoring of regional inundation patterns and hydroperiod in the greater everglades using synthetic aperture radar. Wetlands, 25(1), pp.176-191.

Danklmayer, Andreas., and CHANDRA, Madhukar., 2009. Precipitation induced signatures in SAR images. In: Antennas and Propagation. EuCAP 2009. 3rd European Conference on. IEEE, 2009. p. 3433-3437.

Gondwe, B.R., Hong, S.H., Wdowinski, S. and Bauer-Gottwein, P., 2010. Hydrologic dynamics of the ground-water-dependent Sian Ka'an wetlands, Mexico, derived from InSAR and SAR data. Wetlands, 30(1), pp.1-13.

Horritt, M.S., Mason, D.C. and Luckman, A.J., 2001. Flood boundary delineation from synthetic aperture radar imagery using a statistical active contour model. International Journal of Remote Sensing, 22(13), pp.2489-2507.

Kim, S.W., Wdowinski, S., Amelung, F. and Dixon, T.H., 2005. C-band interferometric SAR measurements of water level change in the wetlands: Examples from Florida and Louisiana. In 2005 IEEE International Geoscience and Remote Sensing Symposium, IGARSS 2005.

Lu, Z. and Kwoun, O.I., 2008. Radarsat-1 and ERS InSAR analysis over southeastern coastal Louisiana: Implications for mapping water-level changes beneath swamp forests. IEEE Transactions on Geoscience and Remote Sensing, 46(8), pp.2167-2184.

Martinis, S., Twele, A. and Voigt, S., 2009. Towards operational near real-time flood detection using a split-based automatic thresholding procedure on high resolution TerraSAR- 
X data. Natural Hazards and Earth System Sciences, 9(2), pp.303-314.

Mason, D.C., Garcia-Pintado, J., Cloke, H.L. and Dance, S.L., 2015. The potential of flood forecasting using a variableresolution global Digital Terrain Model and flood extents from Synthetic Aperture Radar images. Frontiers in Earth Science, 3, p.43.

Mason, D.C., Speck, R., Devereux, B., Schumann, G.J.P., Neal, J.C. and Bates, P.D., 2010. Flood detection in urban areas using TerraSAR-X. IEEE Transactions on Geoscience and Remote Sensing, 48(2), pp.882-894.

Matgen, P., Hostache, R., Schumann, G., Pfister, L., Hoffmann, L. and Savenije, H.H.G., 2011. Towards an automated SARbased flood monitoring system: Lessons learned from two case studies. Physics and Chemistry of the Earth, Parts A/B/C, 36(78), pp.241-252.

Oberstadler, R., Hönsch, H. and Huth, D., 1997. Assessment of the mapping capabilities of ERS-1 SAR data for flood mapping: a case study in Germany. Hydrological processes, 11(10), pp.1415-1425.

Oliver-Cabrera, T. and Wdowinski, S., 2016. InSAR-based mapping of tidal inundation extent and amplitude in Louisiana Coastal Wetlands. Remote Sensing, 8(5), p.393.

Pulvirenti, L., Chini, M., Pierdicca, N., Guerriero, L. and Ferrazzoli, P., 2011. Flood monitoring using multi-temporal COSMO-SkyMed data: Image segmentation and signature interpretation. Remote Sensing of Environment, 115(4), pp.9901002 .

Townsend, P.A., 2001. Mapping seasonal flooding in forested wetlands using multi-temporal Radarsat SAR. Photogrammetric engineering and remote sensing, 67(7), pp.857-864.

Townsend, P.A. and Walsh, S.J., 1998. Modeling floodplain inundation using an integrated GIS with radar and optical remote sensing. Geomorphology, 21(3-4), pp.295-312.

Twele, A., Cao, W., Plank, S. and Martinis, S., 2016. Sentinel1-based flood mapping: a fully automated processing chain. International Journal of Remote Sensing, 37(13), pp.2990-3004.

Wdowinski, S., Amelung, F., Miralles-Wilhelm, F., Dixon, T.H. and Carande, R., 2004. Space-based measurements of sheetflow characteristics in the Everglades wetland, Florida. Geophysical Research Letters, 31(15).

Wdowinski, S., Kim, S.W., Amelung, F., Dixon, T.H., MirallesWilhelm, F. and Sonenshein, R., 2008. Space-based detection of wetlands' surface water level changes from L-band SAR interferometry. Remote Sensing of Environment, 112(3), pp.681-696.

Celik, T., 2010. Change detection in satellite images using a genetic algorithm approach. IEEE Geoscience and Remote Sensing Letters, 7(2), pp.386-390. 